\title{
DETECÇÃO DE SEMENTES DE ARROZ MUTANTE TOLERANTE AO HERBICIDA IMAZETHAPYR ${ }^{1}$
}

\author{
MÁRCIO PACHECO DASILVA ${ }^{2}$, FRANCISCO AMARAL VILLELA ${ }^{3}$, LUCIANABICCADODE ${ }^{4}$, \\ ARIANO MARTINS DE MAGALHÃES JR. ${ }^{5}$, MARIA ÂNGELA ANDRÉ TILLMANN ${ }^{3}$
}

\begin{abstract}
RESUMO - O objetivo deste trabalho foi desenvolver metodologias, fundamentadas no teste de germinação, para detecção de sementes de arroz mutante tolerante ao herbicida imazethapyr. Foram conduzidos dois experimentos, cada um constituído de duas etapas. No experimento 1 , foi utilizada a metodologia do papel umedecido na solução do herbicida. Na primeira etapa, as sementes da cultivar BRS 6 - Chuí e linhagem THI foram submetidas à germinação em papel toalha umedecido em solução com seis concentrações diferentes do herbicida imazethapyr. As avaliações foram realizadas no sétimo e décimo quarto dias. Na segunda etapa, empregando a concentração indicada na etapa anterior, as sementes da linhagem THI e das cultivares BRS 7 - Taim, BRS Pelota, BRS ligeirinho, BR-IRGA 410 e IGRA 417 foram submetidas à germinação em papel toalha umedecido na solução com herbicida imazethapyr a $0,001 \%$ (v/v). As avaliações foram realizadas no sétimo dia. No experimento 2, foi empregada a metodologia de imersão das sementes. Na primeira etapa, sementes da cultivar BRS 6 - Chui e da linhagem THI foram hidratadas em solução com diferentes concentrações do herbicida imazethapyr, e a seguir, submetidas à germinação em papel toalha umedecido em água com avaliação no quarto e no sétimo dia. Na segunda etapa, empregando a concentração indicada na etapa anterior, as sementes da linhagem THI e das cultivares BRS 7 Taim, BRS Pelota, BRS ligeirinho, BR IRGA 410 e IRGA 417 foram hidratadas por 4 horas a $25^{\circ} \mathrm{C}$ em solução de $0,5 \%$ (v/v) e, submetidas ao teste de germinação com avaliação no quarto dia após a semeadura. A metodologia do papel umedecido mostra-se eficiente para detecção de sementes de arroz mutante tolerante ao herbicida imazethapyr e a concentração indicada é de 0,001 \% (v/v) do herbicida diluído em água, com germinação a $30^{\circ} \mathrm{C}$ e avaliação aos sete dias após a semeadura. Na metodologia de imersão em solução, a concentração de 0,5\% (v/v) do herbicida imazethapyr é adequada para a detecção de sementes de arroz mutante tolerante, com germinação a $30^{\circ} \mathrm{C}$ e avaliação aos quatro dias após a semeadura.
\end{abstract}

Termos para indexação: Oryza sativa, mutação, bioensaio, germinação.

\section{IDENTIFICATION OF MUTANT RICE SEEDS TOLERANTTO IMAZETHAPYR HERBICIDE}

ABSTRACT - The aim of this work was to develop methods, based on the germination test, for identification of rice seeds tolerant to imazethapyr herbicide. The method that uses wet paper was developed in two stages. In the first stage the seeds of BRS 6 - Chui cultivar and THI lineage were submitted to germination on towel paper soaked in solutions with six different concentrations of the herbicide, containing $106 \mathrm{~g} / \mathrm{l}$ of the imazethapyr herbicide active ingredient. The evaluations were carried out on day seven and fourteen. In the second stage, we used the concentration indicated in the previous experiment. Seeds of the THI lineage and BRS 7-Taim, BRS Pelota, BRS Ligeirinho, BR-IRGA 410 and IRGA 417 cultivars were submitted to germination on paper towel soaked in a solution containing imazethapyr herbicide at $0.001 \%(\mathrm{v} / \mathrm{v})$, diluted in water, and

${ }^{1}$ Submetido em 12/11/2005. Aceito para publicação em 28/03/2007. Parte da Dissertação de Mestrado do Primeiro Autor, apresentada ao Programa de Pós-Graduação em Ciência e Tecnologia de Sementes. FAEM-UFPel.

${ }^{2}$ Eng. Agrônomo, Responsável Técnico do Pró-Sementes. Passo Fundo RS

\footnotetext{
${ }^{3}$ Eng. Agrônomo. Professor Associado. Departamento de Fitotecnia. FAEMUFpel. Caixa Postal 354, 96010-900. Pelotas-RS

${ }^{4}$ Eng. Agrônomo. Professora da Universidade Católica de Pelotas - UCPel.

${ }^{5}$ Eng. Agrônomo. Pesquisador da EMBRAPA Clima Temperado
} 
evaluations done on day seven. The method that uses immersion of the seeds was developed in two stages. In the first one, seeds of the BRS 6 - Chui cultivar and THI lineage were hydrated in solution with different concentrations of the imazethapyr herbicide, containing $106 \mathrm{~g} / \mathrm{l}$ of the active ingredient, for four hours at $25^{\circ} \mathrm{C}$, and then submitted to germination on paper towel soaked in water, with evaluation on days four and seven. In the second stage, using the concentration indicated in the previous stage, seeds of the THI lineage and BRS 7 - Taim, BRS Pelota, BRS Ligeirinho, BR-IRGA 410 and IRGA 417 cultivars were hydrated for four hours at $25^{\circ} \mathrm{C}$ in $0.5 \%$ solution ( $\mathrm{v} / \mathrm{v})$, diluted in distilled water, and then submitted to the germination test with evaluation on day four after sowing. The concentration indicated for identification of rice seeds tolerant to imazethapyr herbicide is $0.5 \%(\mathrm{v} / \mathrm{v})$ diluted in water, and evaluation done on day four.

Index terms: Oryza sativa, mutation, bioassay, germination.

\section{INTRODUÇÃO}

O arroz constitui-se no principal alimento para cerca de $40 \%$ da população mundial. O Brasil destaca-se como maior produtor sul americano. O Rio Grande do Sul (RS) e Santa Catarina (SC), respondem por quase $60 \%$ da produção nacional em lavouras irrigadas e tecnificadas. Hoje, grande parte da área cultivada no estado do Rio Grande do Sul está infestada como arroz vermelho. A grande limitação para o controle está ligada ao fato do arroz vermelho pertencer a mesma espécie botânica do arroz cultivado e não existir produto químico seletivo capaz de controlar esta planta daninha.

As práticas de controle do arroz vermelho adotadas até o momento tem sido parcial e de baixa eficiência, pois nenhum produto químico seletivo foi capaz de controlar esta planta daninha e com isso o problema vem se agravando. Com relação às demais plantas nocivas, na quase totalidade das áreas cultivadas, os produtores utilizam o controle químico, com o emprego de alternativas eficientes oferecidas pelo mercado.

O desenvolvimento de novas cultivares de arroz irrigado é uma necessidade constante, seja para aumento de produtividade pela troca de uma cultivar por outra mais produtiva ou para que o produtor possa empregar estratégias de uso mais racional do solo, da água, manejo de plantas daninhas e dos insumos em geral que possibilitem aumento da produção e renda. Uma alternativa para superar o atual patamar de produtividade das modernas cultivares de arroz irrigado é a utilização de linhagens resistentes ou tolerantes a herbicidas. Culturas alteradas para resistência a herbicidas podem favorecer a utilização de herbicidas de amplo espectro de atuação e possibilitar o uso de produtos menos tóxicos e mais facilmente degradáveis no solo, aumentando as opções no combate a plantas daninhas. Genes que conferem resistência a herbicidas podem ser encontrados na natureza, ou obtidos por meio de indução de mutação (Brasileiro e
Dusi,1999).

Neste contexto, é possível dividir a estratégia em dois grupos. O primeiro,relativo ao desenvolvimento de linhagens transgênicas resistentes a herbicidas e, o segundo, pelo desenvolvimento de linhagens mutantes tolerantes a herbicidas.

A mutação consiste em fontes primárias de variabilidade genética, resultantes de alterações do DNA que modificam o genótipo do indivíduo, podendo ser espontâneas ou induzidas (Pinto, 1995). As mutações espontâneas são raras e não direcionadas, sendo limitado seu uso no melhoramento de plantas, pois a chance que ocorra espontaneamente uma mutação favorável é muito pequena. Portanto, ao referir-se a linhagens mutantes, pensa-se em mutação induzida. As linhagens mutantes, quer sejam obtidas por radiação, agentes químicos ou variação somaclonal não sofrem restrições do ponto de vista legal no Brasil, sendo permitido comercialização e consumo, atualmente, sem nenhuma restrição.

O desenvolvimento de linhagens mutantes tolerantes a herbicidas inibidores da enzima acetolactato sintase (ALS) pode ser uma alternativa para o controle do arroz vermelho, criando oportunidade para aplicação de novas estratégias e aumento da flexibilidade no manejo e controle de invasoras (Duke,1996).

O imazethapyr é um herbicida do grupo das imidazolinonas, sistêmico, pós-emergente e seletivo para soja, mas não seletivo para arroz, com dose recomendada de um litro por hectare. O mecanismo de ação é a inibição nãocompetitiva da enzima acetolactato sintetase ou acetohydroxi sintetase (AHAS), na rota de síntese dos aminoácidos ramificados valina, leucina e isoleucina. Os sintomas das plantas sob efeito dos herbicidas inibidores da ALS incluem paralisação do crescimento, amarelecimento dos meristemas e redução do sistema radical (Vargas et al., 1999). A AHAS é uma enzima encontrada nas bactérias, em determinados outros microorganismos e em plantas, capaz de catalisar a primeira 
etapa da biossíntese dos aminoácidos essenciais isoleucina e valina. A ação do herbicida induz a inibição da AHAS e leva a uma diminuição na síntese de proteína, conseqüência letal para planta. Uma única substituição do aminoácido no gene da AHAS é suficiente para alterar o local obrigatório para imidazolinonas, de maneira que o herbicida imazetahapyr deixe de inibir a AHAS, resultando em um fenótipo tolerante ao herbicida (CFIA, 2002).

Estudos para identificação de plantas tolerantes são de elevada importância para os programas de melhoramento, para estudos de fluxo gênico, campos de produção de sementes e comercialização de grãos. Desta maneira, a identificação de cultivares mutantes resistentes requer testes específicos, com vistas a verificação da atividade do gene alterado.

O desenvolvimento de metodologias de análise que permitam avaliar a qualidade fisiológica e a pureza genética da semente torna-se fundamental para que o produtor possa adotar esta nova tecnologia de forma segura. Esta metodologia deve ser eficiente, rápida, de baixo custo. A utilização do principio do teste de germinação favorece pela padronização, possibilitando sua adoção de forma rotineira pelos laboratórios.

O objetivo deste trabalho foi desenvolver uma metodologia fundamentada no teste de germinação, que permita a identificação de sementes da linhagem TH I, tolerante ao herbicida imazethapyr.

\section{MATERIAL E MÉTODOS}

O trabalho foi conduzido no Laboratório de Cultura de Tecidos da Estação Experimental Terras Baixas, pertencente a Embrapa Clima Temperado. Foram utilizadas sementes da linhagem THI, tolerante ao herbicida imazethapyr e das cultivares BRS 6 - Chui, BRS 7 - Taim, BRS Pelota, BRS Ligeirinho, BR-IRGA 410 e IRGA 417.

Foram realizados dois experimentos, com base no teste de germinação, o primeiro utilizando papel umedecido e o segundo imersão das sementes em solução de herbicida.

Cada experimento foi dividido em duas etapas. A primeira visou a determinação de uma concentração do herbicida capaz de inibir a germinação da cultivar BRS 6 - Chui, sem afetar o desenvolvimento da linhagem tolerante. A segunda avaliou o comportamento de sementes de outras cultivares de arroz na presença de solução com concentração indicada na primeira etapa.

Todas as sementes foram submetidas a tratamento de superação de dormência utilizando pré-secagem a $50^{\circ} \mathrm{C}$, durante 96 horas, em estufa com circulação de ar
(Brasil,1992).

\section{Experimento 1 - Metodologia do papel umedecido na solução do herbicida}

Na primeira etapa, as sementes da cultivar BRS 6 - Chui e linhagem THI foram submetidas à germinação em papel toalha umedecido em soluções com sete concentrações diferentes do herbicida: 0; 0,001; 0,005; 0,01; 0,05; 0,1 e 0,5\% (v/v), diluídas em água destilada, contendo $106 \mathrm{~g} / \mathrm{l}$ do principio ativo ( 2-(4,5-dihidro-4-metil-4-(1-metiletil)-5-oxo1H-imidazol-2-ilo)-5-etil-3-piridinacarboxílico - imazethapyr e avaliação no sétimo e décimo quarto dias. Na segunda etapa, as sementes da linhagem THI e das cultivares BRS 7 -Taim, BRS Pelota, BRS Ligeirinho, BR-IRGA 410 e IRGA 417 foram submetidas à germinação em papel toalha umedecido na solução do herbicida Imazethapyr a 0,001% (v/v) diluída em água destilada e avaliação no sétimo dia.

Para cada concentração e/ou cultivar, no teste de germinação, foram utilizadas quatro amostras de 50 sementes. O substrato foi umedecido com quantidade equivalente a 2,5 seu peso seco e acondicionados em sacos plásticos abertos na extremidade superior para facilitar a ventilação e evitar contaminação do germinador e contato entre rolos contendo a solução em diferentes concentrações. O germinador foi regulado à temperatura constante de $30^{\circ} \mathrm{C}$. Em todas as avaliações foram realizadas contagem e medição do comprimento total das plântulas normais. Para a obtenção dos valores médios do comprimento total de plântulas, foi feito somatório do comprimento e dividido pelo número de plântulas normais.

\section{Experimento 2 - Metodologia da imersão em solução de herbicida}

Na primeira etapa, as sementes da cultivar BRS 6 - Chui e da linhagem THI foram hidratadas em solução com nove concentrações diferentes do herbicida, 0; 0,001; 0,005; 0,01; 0,05; 0,1: 0,5; 1,0 e 5,0\% (v/v), diluídas em água destilada, contendo $106 \mathrm{~g} / \mathrm{l}$ do principio ativo imazethapyr por quatro horas a $25^{\circ} \mathrm{C}$. A seguir, as sementes foram lavadas em água corrente, submetidas à germinação em papel toalha umedecido com água e avaliação no quarto e sétimo dias após a semeadura. Na segunda etapa, as sementes da linhagem THI e das cultivares BRS 7 -Taim, BRS Pelota, BRS Ligeirinho, BRIRGA 410 e IRGA 417 foram hidratadas por quatro horas em solução com concentração de 0,5\% (v/v), diluída em água destilada. Após este tempo, as sementes foram lavadas em água corrente e submetidas à germinação em papel toalha 
umedecido com água e avaliação no quarto dia após a semeadura.

Para cada concentração e/ou cultivar, no teste de germinação foram utilizadas quatro amostras de 50 sementes, seguindo os demais procedimentos descritos no experimento 1.

O tempo de quatro horas de hidratação foi definido segundo Ayala et al., (2001) que verificaram maior taxa de absorção de água pelas sementes de arroz nas primeiras horas, se estabilizando a partir das seis horas.

Nos dois experimentos utilizou-se delineamento experimental inteiramente casualizado, com quatro repetições em esquema fatorial A x B (cultivar x concentração do herbicida). As médias dos tratamentos foram comparadas pelo teste de Tukey ao nível de 5\% de probabilidade.

\section{RESULTADOS E DISCUSSÃO}

\section{Experimento 1 - Metodologia do papel umedecido na} solução do herbicida

A análise da variação mostrou diferença significativa, entre cultivares e concentrações, para todas as variáveis analisadas, indicando a possibilidade de detecção de sementes de arroz tolerante ou não ao herbicida por este método, sendo altamente significativa à interação entre genótipos e concentrações.

De maneira similar, Magalhães Jr. et al. (2000) e Lilge et al. (2003) utilizando metodologia do papel umedecido para detecção de sementes de arroz geneticamente modificado tolerante ao principio herbicida glufosinato de amônio obtiveram resultados promissores em relação à detecção de sementes de arroz tolerante, empregando o princípio do teste de germinação. Neste caso, é importante destacar que houve uma introdução do gene de resistência na planta conferindo uma tolerância ao glufosinato de amônio, enquanto que, no caso da linhagem THI a mutação obtida confere tolerância parcial ao princípio herbicida imazethapyr.

Por outro lado, Nedel (1998) descreve metodologia para a detecção de milho resistente ao herbicida imazethapyr utilizando o princípio do teste de germinação e com avaliação aos sete dias. Entretanto, em soja, os testes também utilizam o princípio do teste de germinação, mas apontam variações, podendo ser germinação em papel umedecido com a solução, germinação em papel e após algum tempo ser colocada a solução no rolo, ou a germinação conforme Brasil (1992) e depois as plântulas aspergidas com solução do herbicida.

Diferenças significativas foram observadas na avaliação aos sete dias nas respostas da cultivar BRS 6 - Chui e linhagem
THI quando as sementes foram expostas a concentração 0,001 (v/v) do herbicida , onde constata-se que a linhagem THI foi capaz de manter a percentagem de germinação semelhante à testemunha na presença do herbicida (Tabela 1) e a cultivar BRS 6 -Chui foi fortemente afetada apresentando percentagem muito baixa e reduzido crescimento (Figura 1). Todavia, as concentrações acima de 0,001\% afetaram tanto THI como BRS 6 -Chui, sendo que concentrações superiores a essa inibiram a germinação das sementes da cultivar BRS Chui. A inibição da germinação das sementes da linhagem THI somente ocorreu nas concentrações iguais ou superiores a 0,05\%. Nesta concentração, houve uma redução na germinação de dois pontos percentuais em relação à testemunha. No que se refere ao comprimento de plântulas (Figura 2), a linhagem THI teve seu crescimento parcialmente afetado pela presença

TABELA 1- Dados médios de germinação (\%) aos sete dias de sementes de arroz da cultivar BRS 6 - Chui e linhagem THI, após semeadura em rolo umedecido ou não em solução com diferentes concentrações de herbicida imazethapyr.

\begin{tabular}{lcc}
\hline \multirow{2}{*}{ Concentração (\%) } & \multicolumn{2}{c}{ Germinação } \\
\cline { 2 - 3 } & Linhagem THI & BRS 6 - CHUI \\
\hline 0,0 & $82 \mathrm{aA}$ & $83 \mathrm{aA}$ \\
0,001 & $78 \mathrm{aA}$ & $3 \mathrm{bB}$ \\
0,005 & $60 \mathrm{aA}$ & $0 \mathrm{bC}$ \\
0,01 & $11 \mathrm{aB}$ & $0 \mathrm{bC}$ \\
0,05 & $0 \mathrm{aC}$ & $0 \mathrm{aC}$ \\
0,1 & $0 \mathrm{aC}$ & $0 \mathrm{aC}$ \\
0,5 & $0 \mathrm{aC}$ & $0 \mathrm{aC}$ \\
\hline $\mathrm{CV}(\%)$ & \multicolumn{3}{c}{10,1} \\
\hline
\end{tabular}

Médias seguidas da mesma letra, minúscula nas linhas e maiúscula nas colunas, não diferem entre si pelo teste de Tukey a $5 \%$ de probabilidade.

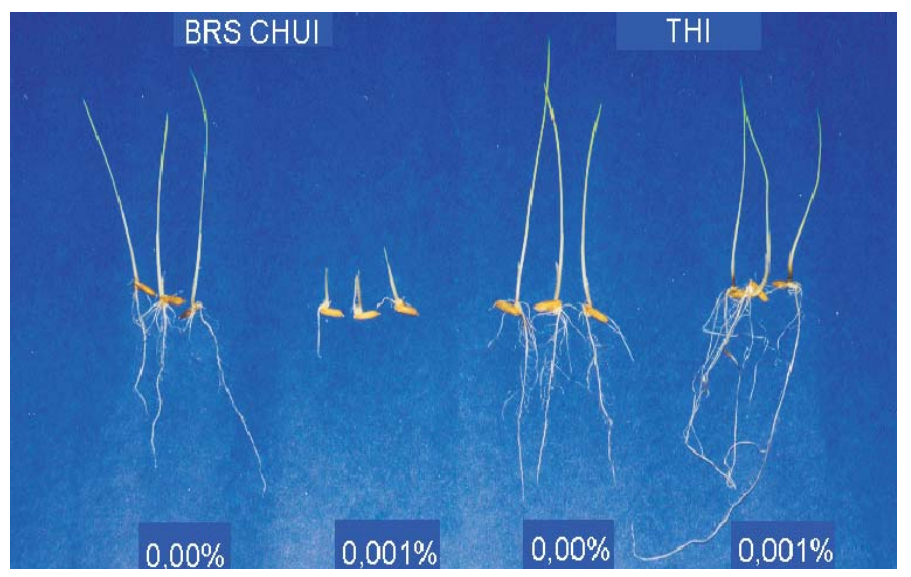

FIGURA 1. Plântulas de arroz da linhagem THI e da cultivar BRS 6 - Chui aos sete dias após semeadura em rolo sem e com solução de $0,001 \%$ (v/v) do herbicida imazethapyr. 


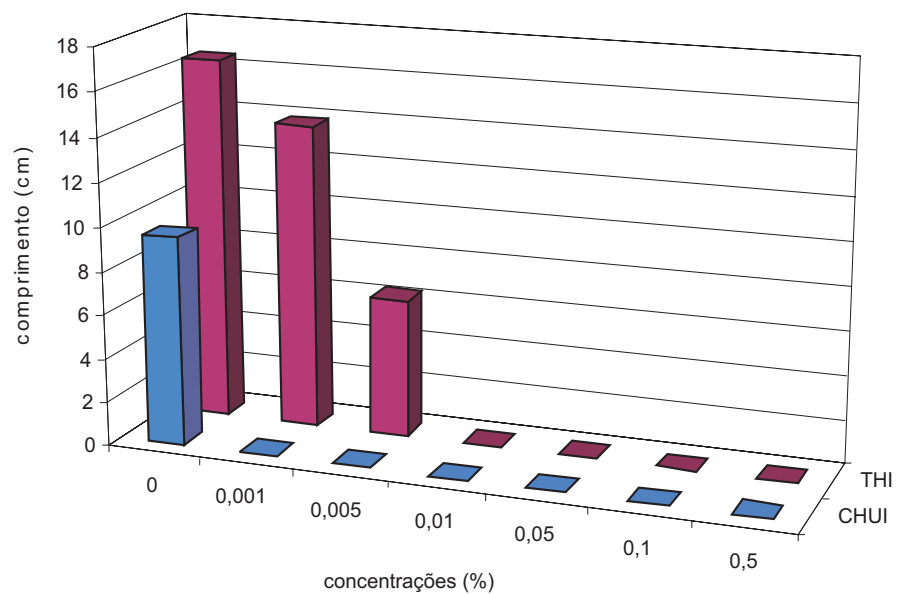

FIGURA 2. Efeito aos sete dias após semeadura em rolo umedecido sem e com diferentes concentrações do herbicida imazethapyr no comprimento $(\mathrm{cm})$ total da plântula de arroz da cultivar BRS 6 - Chui e linhagem THI.

do herbicida, apresentando em média plântulas menores que a testemunha. Porém, a cultivar BRS 6 Chui foi prejudicada pela presença do herbicida. Na avaliação aos 14 dias (Tabela 2), os resultados mostram a mesma tendência verificada aos sete dias, sendo a cultivar BRS 6 - Chui afetada por todas a concentrações do herbicida, apresentando plântulas anormais. A linhagem THI apresentou valores semelhantes de germinação na concentração de 0,001(v/v), tanto aos sete como aos quatorze dias, o que evidencia a possibilidade de identificação e avaliação de sementes de arroz mutante tolerante ao herbicida imazethapyr nesta concentração, aos sete dias.

Na segunda etapa, o comportamento das cultivares BRS Pelota, BRS Ligeirinho, BRS 7 - Taim, BR-IRGA 410 e IRGA

TABELA 2. Dados médios de germinação (\%) aos 14 dias de sementes de arroz da cultivar BRS 6 - Chui e linhagem THI, após semeadura em rolo umedecido ou não em solução com diferentes concentrações de herbicida imazethapyr.

\begin{tabular}{lcc}
\hline \multirow{2}{*}{ Concentração (\%) } & \multicolumn{2}{c}{ Germinação } \\
\cline { 2 - 3 } & Linhagem THI & BRS 6 - CHUI \\
\hline 0,0 & $83 \mathrm{aA}$ & $86 \mathrm{aA}$ \\
0,001 & $79 \mathrm{aA}$ & $1 \mathrm{bB}$ \\
0,005 & $78 \mathrm{aA}$ & $1 \mathrm{bB}$ \\
0,01 & $7 \mathrm{aB}$ & $1 \mathrm{aB}$ \\
0,05 & $0 \mathrm{aC}$ & $0 \mathrm{aB}$ \\
0,1 & $0 \mathrm{aC}$ & $0 \mathrm{aB}$ \\
0,5 & $0 \mathrm{aC}$ & $0 \mathrm{aB}$ \\
\hline CV $(\%)$ & \multicolumn{3}{c}{9,8} \\
\hline
\end{tabular}

Médias seguidas da mesma letra, minúscula nas linhas e maiúscula nas colunas, não diferem entre si pelo teste de Tukey a $5 \%$ de probabilidade.
417 em relação à concentração indicada na etapa anterior, pode ser verificado. A germinação das sementes das cultivares foi bastante prejudicada pela solução 0,001(v/v), mostrando diferença significativa em relação à linhagem THI (Tabela 3). O comprimento total das plântulas das cultivares também foi muito afetado pela solução (Figura 3), evidenciando que a metodologia é adequada para detecção de cultivares tolerantes ao herbicida imazethapyr (Figura 4).

É importante salientar que as sementes, das cultivares não tolerantes, na presença do produto ou mesmo da cultivar tolerante em concentração mais elevada iniciam a fase visível de germinação, todavia a ação do herbicida não permite seu

TABELA3. Dados médios da germinação (\%), aos sete dias em sementes de arroz, de diferentes cultivares, após semeadura em rolo umedecido em solução com concentrações de 0,001 (\%) (v/v) do herbicida imazethapyr.

\begin{tabular}{lcc}
\hline Cultivar & \multicolumn{2}{c}{ Germinação } \\
\cline { 2 - 3 } & Com herbicida & Sem herbicida \\
\hline LTH & $79 \mathrm{aA}$ & $82 \mathrm{aBC}$ \\
BRS PELOTA & $0 \mathrm{bB}$ & $70 \mathrm{aD}$ \\
BRS 7 - TAIM & $0 \mathrm{bB}$ & $97 \mathrm{aA}$ \\
BRS LIGEIRINHO & $0 \mathrm{bB}$ & $75 \mathrm{aCD}$ \\
BR-IRGA 410 & $0 \mathrm{bB}$ & $84 \mathrm{aB}$ \\
IRGA 417 & $0 \mathrm{bB}$ & $70 \mathrm{aD}$ \\
\hline CV $(\%)$ & \multicolumn{2}{c}{10,4} \\
\hline
\end{tabular}

Médias seguidas da mesma letra, minúscula nas linhas e maiúscula nas colunas, não diferem entre si pelo teste de Tukey a $5 \%$ de probabilidade.

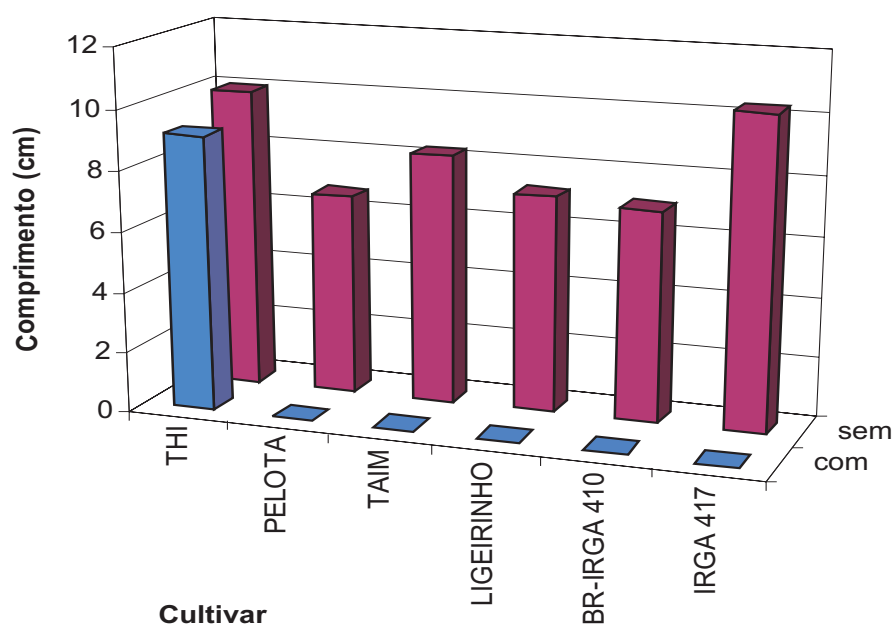

FIGURA 3. Dados médios aos sete dias de comprimento total de plântulas de arroz, de diferentes cultivares, após semeadura em rolo umedecido ou não em solução com concentrações de 0,001 (\%) (v/v) do herbicida imazethapyr. 


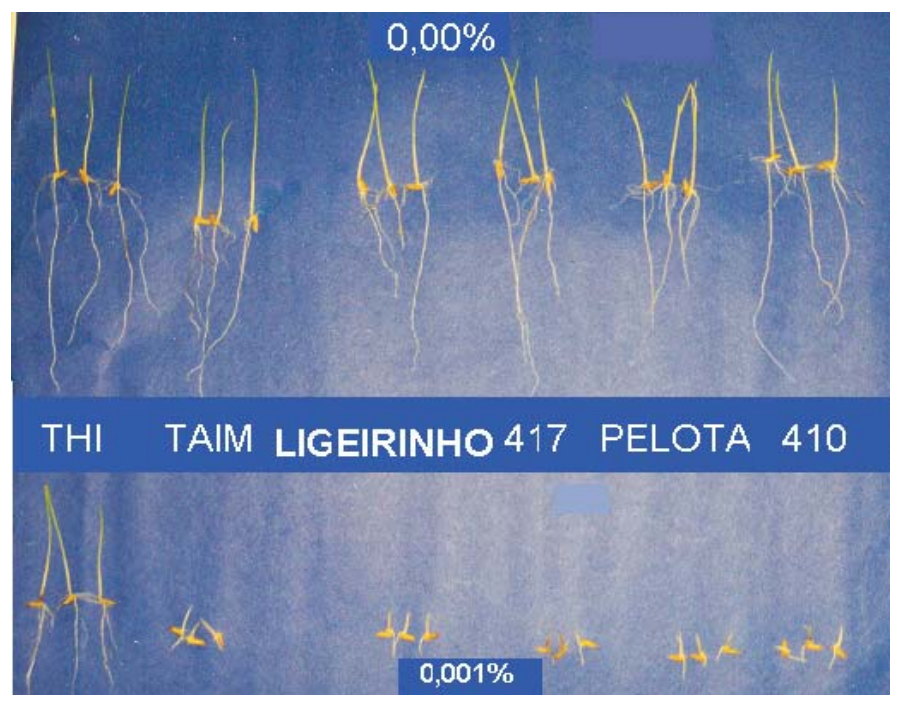

FIGURA 4. Plântulas de arroz de diferentes cultivares aos sete dias após a semeadura em rolos umedecidos sem e com a solução $0,001 \%(v / v)$ do herbicida imazethapyr.

prosseguimento. Assim ocorre emissão de raízes primárias e coleóptilo que, entretanto, não se desenvolvem e dessa forma são consideradas plântulas anormais.

Dois aspectos que devem ser considerados na metodologia são impedir o contato dos rolos com a parede do germinador, para evitar que o produto seja lixiviado pela água que escorre nas paredes, proceder a semeadura a mais de 3 cm da margem superior do rolo, para não permitir escape de plântulas por um eventual escorrimento do produto.

\section{Experimento 2 - Metodologia da imersão em solução} de herbicida

A análise da variação mostrou diferença significativa, entre genótipos e concentrações testadas, para todas as variáveis analisadas, indicando a possibilidade de detecção e separação de sementes de arroz tolerante ou não ao herbicida imazethapyr por este método, sendo altamente significativa a interação entre genótipos e concentrações.

Utilizando metodologia do papel umedecido e por imersão para detecção de sementes de arroz geneticamente modificado resistente ao princípio herbicida glufosinato de amônio, Magalhães Jr. et al. (2000) e Lilge et al., (2003) obtiveram resultados satisfatórios em relação à detecção de sementes tolerantes, através da germinação. Metodologia para a detecção de milho resistente ao herbicida imazethapyr utilizando o princípio do teste de germinação e com avaliação aos sete dias, foi descrita por Nedel (1998).
Diferenças significativas foram observadas na avaliação aos quatro dias nas respostas da cultivar BRS 6 - Chui e linhagem THI quando as sementes foram expostas à concentração 0,5 (v/v) do herbicida, onde constata-se que a linhagem THI foi capaz de resistir a presença do herbicida, mantendo a percentagem de germinação semelhante à testemunha (Tabela 4), mas com crescimento reduzido (Figura 5), e a cultivar BRS 6 -Chui teve germinação nula. Em concentrações abaixo de 0,5\% (v/v), tanto a linhagem THI como a cultivar BRS 6 Chui resistiram a presença do herbicida, embora a concentração $0,1 \%$ tenha afetado a germinação da

TABELA4. Dados médios da germinação (\%) aos quatro dias, de sementes de arroz, cultivar BRS 6 - Chui e linhagem THI, após hidratação por 4 horas a $25^{\circ} \mathrm{C}$, em soluções sem e com diferentes concentrações herbicida imazethapyr (v/v).

\begin{tabular}{lcc}
\hline \multirow{2}{*}{ Concentração (\%) } & \multicolumn{2}{c}{ Germinação } \\
\cline { 2 - 3 } & Linhagem THI & BRS 6 - CHUI \\
\hline 0,0 & $80 \mathrm{aA}$ & $84 \mathrm{aA}$ \\
0,001 & $80 \mathrm{aA}$ & $74 \mathrm{aA}$ \\
0,005 & $80 \mathrm{aA}$ & $68 \mathrm{aA}$ \\
0,01 & $80 \mathrm{aA}$ & $65 \mathrm{aA}$ \\
0,05 & $75 \mathrm{aA}$ & $47 \mathrm{bB}$ \\
0,1 & $79 \mathrm{aA}$ & $26 \mathrm{bB}$ \\
0,5 & $79 \mathrm{aA}$ & $0 \mathrm{bC}$ \\
1,0 & $10 \mathrm{aB}$ & $0 \mathrm{bC}$ \\
5,0 & $0 \mathrm{aC}$ & $0 \mathrm{aC}$ \\
\hline CV (\%) & \multicolumn{2}{c}{11,9} \\
\hline
\end{tabular}

Médias seguidas da mesma letra, minúscula nas linhas e maiúscula nas colunas, não diferem entre si pelo teste de Tukey a $5 \%$ de probabilidade.

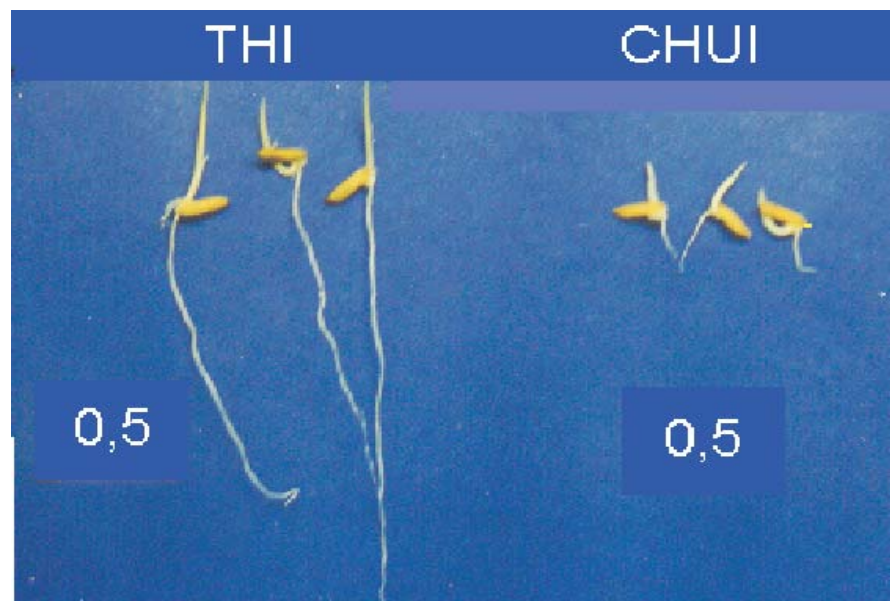

FIGURA 5. Plântulas de arroz da linhagem THI e da cultivar BRS 6 - Chui aos quatro dias após hidratação por 4 horas a $25^{\circ} \mathrm{C}$ em solução com $0,5 \%$ do herbicida imazethapyr. 
cultivar BRS Chui. Todavia, as concentrações acima de 0,5\% afetaram tanto THI como BRS 6 - Chui. No que se refere ao comprimento de plântulas (Figura 6), a cultivar BRS 6 Chui teve seu crescimento mais afetado do que a linhagem THI.

Aos sete dias, as avaliações devem ser feitas com muito cuidado (Tabela 5 e Figura 7), pois a cultivar BRS 6 - Chui foi afetada por todas a concentrações do herbicida, embora podendo até formar plântulas normais. A linhagem THI apresentou diminuição de germinação na solução com concentração de $0,5 \%$ do herbicida imazethapyr diluído em água (v/v), evidenciando que foi afetada pelo herbicida. Outro aspecto a salientar, é o fato da cultivar BRS 6 Chui aos sete dias, apesar de apresentar crescimento acentuado, principalmente de raízes, pode formar plântulas normais, o que dificulta a avaliação nesta data (Figura 7).

Na segunda etapa é possível observar o comportamento das cultivares BRS Pelota, BRS Ligeirinho, BRS 7 - Taim, BR-IRGA 410 e IRGA 417 em relação à concentração indicada na etapa anterior (Tabela 6). Constata-se que essa concentração inibiu a germinação das sementes das cultivares, com ocorrência de germinação, embora muito baixa, na cultivar BRS Pelota. O comprimento das plântulas das cultivares foi prejudicado pela solução 0,5 (v/v) (Figura 8), mostrando diferença significativa em relação à Linhagem THI, evidenciando que a metodologia é adequada para identificação de cultivares tolerantes ao herbicida imazethapyr (Figura 9). Todavia, também é importante salientar que as cultivares aos sete dias podem formar plântulas mais desenvolvidas, dificultando as avaliações, o que evidencia

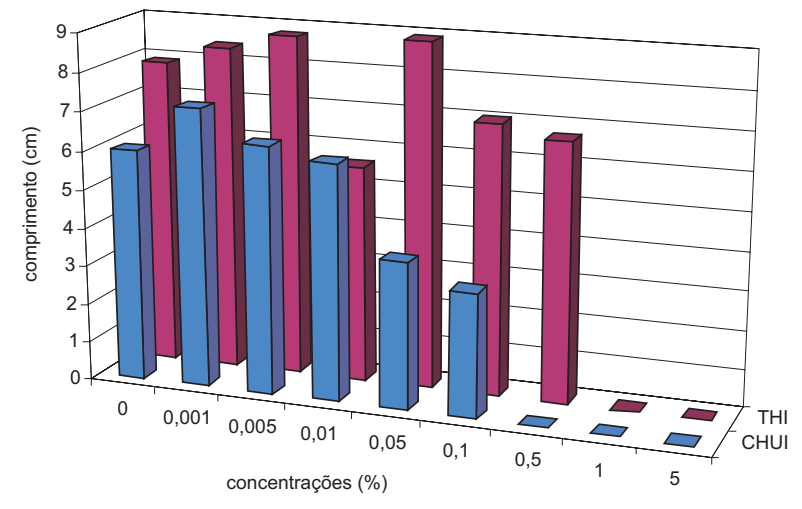

FIGURA 6. Comprimento total $(\mathrm{cm})$ de plântulas de arroz, das cultivares BRS 6-Chui e linhagem THI, aos quatro dias após hidratação por 4 horas a $25^{\circ} \mathrm{C}$ em solução sem e com herbicida imazethapyr em diferentes.
TABELA 5- Dados médios da germinação (\%) aos sete dias, de sementes de arroz, cultivar BRS 6 - Chui e linhagem THI, após hidratação por 4 horas a $25^{\circ} \mathrm{C}$ em soluções sem e com diferentes concentrações herbicida imazethapyr (v/v).

\begin{tabular}{lcc}
\hline \multirow{2}{*}{ Concentração (\%) } & \multicolumn{2}{c}{ Germinação } \\
\cline { 2 - 3 } & Linhagem THI & BRS-6 CHUI \\
\hline 0,0 & $82 \mathrm{aA}$ & $89 \mathrm{aA}$ \\
0,001 & $81 \mathrm{aA}$ & $83 \mathrm{aAB}$ \\
0,005 & $79 \mathrm{aAB}$ & $79 \mathrm{aAB}$ \\
0,01 & $78 \mathrm{aAB}$ & $69 \mathrm{aBC}$ \\
0,05 & $74 \mathrm{aAB}$ & $54 \mathrm{aC}$ \\
0,1 & $72 \mathrm{aAB}$ & $26 \mathrm{bD}$ \\
0,5 & $65 \mathrm{aB}$ & $0 \mathrm{bE}$ \\
\hline CV $(\%)$ & \multicolumn{3}{c}{10,6} \\
\hline
\end{tabular}

Médias seguidas da mesma letra, minúscula nas linhas e maiúscula nas colunas, não diferem entre si pelo teste de Tukey a $5 \%$ de probabilidade.

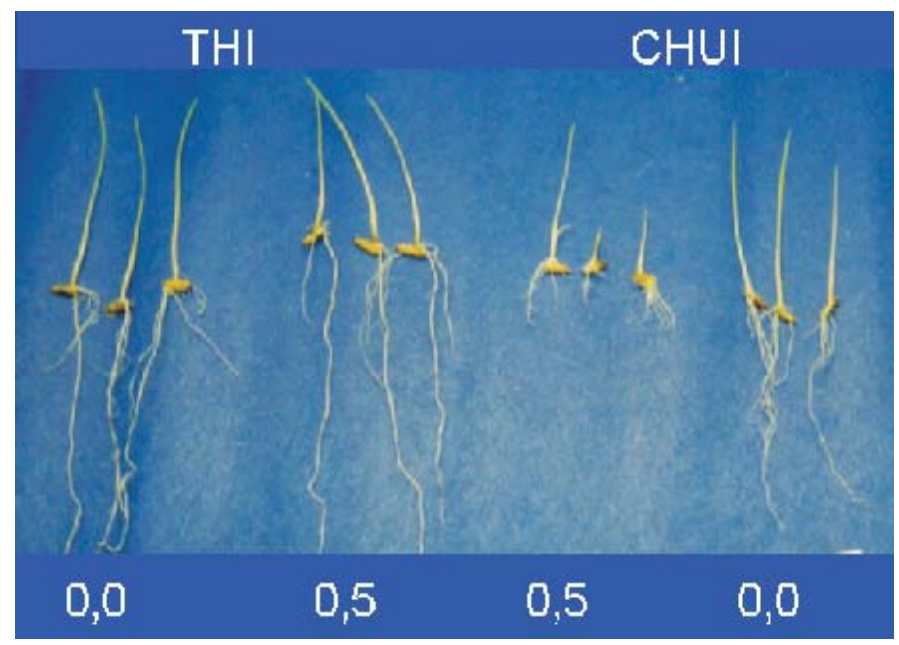

FIGURA 7. Plântulas de arroz da linhagem THI e da cultivar BRS 6 - Chui aos sete dias após hidratação, por 4 horas a $25^{\circ} \mathrm{C}$ em soluções sem e com $0,5 \%$ do herbicida imazethapyr (v/v).

TABELA6- Dados médios de germinação (\%) aos quatro dias de sementes de arroz, de diferentes cultivares, após hidratação por 4 horas a $25^{\circ} \mathrm{C}$ em soluções sem e $\operatorname{com} 0,5 \%$ do herbicida imazethapyr (v/v).

\begin{tabular}{lcc}
\hline \multirow{2}{*}{ Cultivar } & \multicolumn{2}{c}{ Germinação } \\
\cline { 2 - 3 } & Com herbicida & Sem herbicida \\
\hline LTH & $77 \mathrm{aA}$ & $80 \mathrm{aA}$ \\
BRS PELOTA & $1 \mathrm{bB}$ & $73 \mathrm{aA}$ \\
BRS 7 - TAIM & $0 \mathrm{bB}$ & $92 \mathrm{aB}$ \\
BRS LIGEIRINHO & $0 \mathrm{bB}$ & $64 \mathrm{aB}$ \\
BR-IRGA 410 & $0 \mathrm{bB}$ & $87 \mathrm{aB}$ \\
IRGA 417 & $0 \mathrm{bB}$ & $74 \mathrm{aC}$ \\
\hline CV $(\%)$ & \multicolumn{3}{c}{8,2} \\
\hline
\end{tabular}

Médias seguidas da mesma letra, minúscula nas linhas e maiúscula nas colunas, não diferem entre si pelo teste de Tukey a $5 \%$ de probabilidade. 


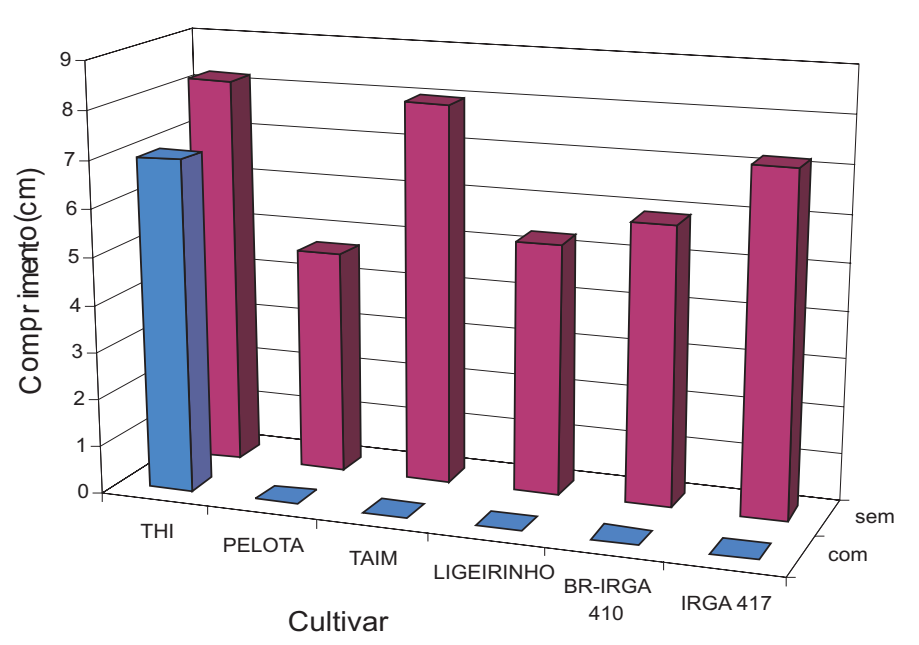

FIGURA 8. Comprimento total (cm) de plântulas de arroz aos quatro dias, de diferentes cultivares, após hidratação por 4 horas a $25^{\circ} \mathrm{C}$ em solução sem e com $0,5 \%$ do herbicida imazethapyr (v/v) antes da semeadura.

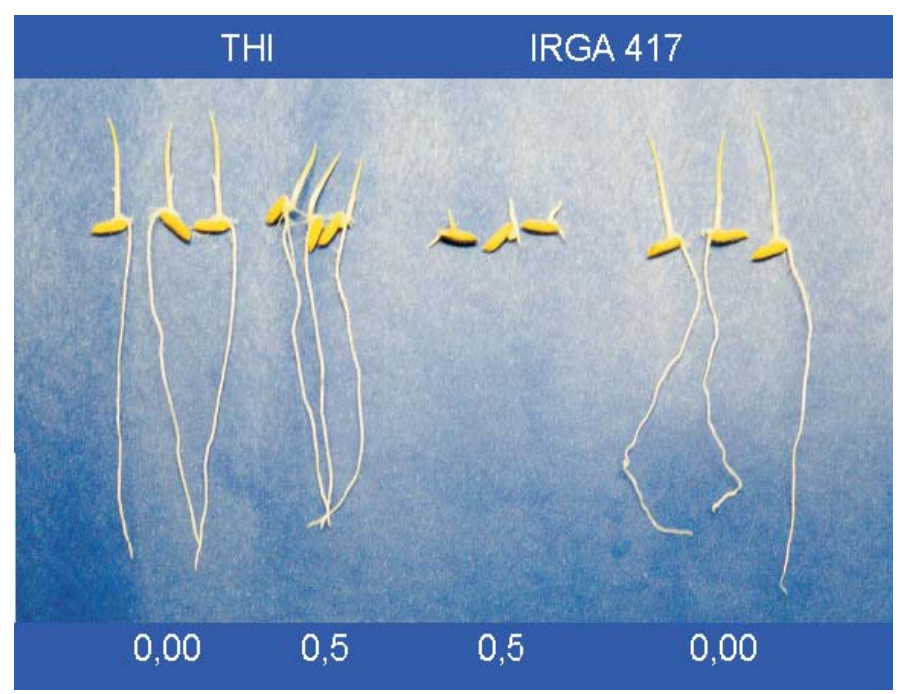

FIGURA 9. Plântulas de arroz da linhagem THI e da cultivar IRGA 417 aos quatro dias, após hidratação por 4 horas a $25^{\circ} \mathrm{c}$ em soluções sem e com $0,5 \%$ do herbicida imazethapyr (v/v).

que as avaliações devem ser realizadas efetivamente aos quatro dias após a semeadura em rolo.

É valido destacar que as sementes das cultivares não tolerantes ao herbicida, na presença do produto, ou mesmo da cultivar tolerante, em concentração mais elevada, iniciam a fase visível de germinação, mas a ação do herbicida impede sua evolução, ou seja, começa a emissão de raízes primárias e coleóptilo que, todavia, não se desenvolvem e por isso são consideradas plântulas anormais.

\section{CONCLUSÕES}

A metodologia do papel umedecido mostra-se eficiente para detecção de sementes de arroz mutante tolerante ao herbicida imazethapyr, e a concentração indicada é de 0,001 \% (v/v) do herbicida diluído em água, com germinação a $30^{\circ} \mathrm{C}$ e avaliação aos sete dias após a semeadura.

Na metodologia de imersão em solução, a concentração de $0,5 \%(\mathrm{v} / \mathrm{v})$ do herbicida imazethapyr é adequada para a detecção de sementes de arroz mutante tolerante, com germinação a $30{ }^{\circ} \mathrm{C}$ e avaliação aos quatro dias após a semeadura.

\section{REFERÊNCIAS}

AYALA, L. ; TILLMANN, M. A. A. ; DOGE, L. B. ; VILLELA, F. A.; MAGALHAES JR., A.M.; SILVA, M. P. . Tetrazolium test for identification of transgenic rice seeds tolerant to herbicide. Seed Science And Technology, Zürich, v. 30, n. 2, p. 431-436, 2002.

BRASIL, Ministério da Agricultura e da Reforma Agrária. Regras para análise de sementes. Brasília: SNDA/DNDV/CLAV, 1992: 365p.

BRASILEIRO, A.C.M.; DUSI, D. M. de A., Transformação genética de plantas. In: TORRES, A. C.; CALDAS, L. S.; BUSO, J. A. Ed. Cultura de tecidos e transformação genética de Plantas. Brasília: Embrapa-SPI / Embrapa-CNPH, 1999. p.679-735. v.2.

CANADIAN FOOD INSPECTION AGENCY, Decision Document DD2002-40 Determination of the Safety of BASF's Imqazethapyr Tolerant (CLEARFIELD ${ }^{\mathrm{TM}}$ ) Rice. http://www.inspection.gc.ca

DUKE, S.O. Herbicide resistant crops. Boca Raton. Flórida, Lewis Publishers. 1996. 420p.

LILGE, C.G.; TILLMANN, M.Â.A.; VILLELA, F.A.; DODE, L.B.. Identificaçao de sementes de arroz transformado geneticamente resistente ao herbicida glufosinato de amônio Revista Brasileira de Sementes, Pelotas, v. 25, n. 1, p. 87-94 2003.

MAGALHÃES JR. A. M.de; FRANCO, D. F.; ANDRES, A.; ANTUNES, P.; LUZZARDI, R.; DODE, L. B.; TILLMANN, M. A. A.; SILVA, M. P. Método para identificação de semente de arroz transgênico resistente ao herbicida glufosinato de amônio. Agropec. Clima Temperado, Pelotas: v. 3, n.1, p.31-38,2000.

NEDEL, J.L. Avaliando a semente transgênica. Seed News, Pelotas. v.2, n.3, p. 30, 1998.

PINTO, R. J. B.; Introdução ao melhoramento genético de plantas. Maringá: EDUEM, 1995. 275p.

VARGAS, L; SILVA, A.A.; BORÉM,A.; REZENDE, S.T.; FERREIRA, F. A.; SEDIYAMA, T. ; Resistencia de plantas daninhas a herbicidas. Viçosa, MG, 1999. 131p.

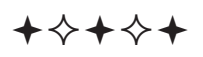

